\title{
O NEGRO NA ORDEM JURÍDICA BRASILEIRA
}

\author{
Eunice Aparecida de Jesus Prudente \\ Professora Assistente do Departamento de Direito do Estado da \\ Faculdade de Direito da Universidade de São Paulo
}

\begin{abstract}
Resumo: No Brasil à escala sócio-econômica corresponde uma escala racial, na qual o contingente negro do povo, encontra-se nas camadas subempregadas e carentes, a despeito da igualdade jurídica, estabelecida pela Constituição Federal. Contradiçōes da própria ordem jurídica, educação oficial preconceituosa, ação contínua dos meios de comunicação de massa veiculando estereótipos, mantém a situação terrível em que se encontram os afrobrasileiros. A discriminação racial no mercado de trabalho. Urgia mudanças nesta ordem injusta com a tipificação da discriminação racial como crime, reavaliação da presença do negro na História do Brasil, autêntica participação política do povo brasileiro.
\end{abstract}

Abstracts: In Brazil the racial scale is juxtaposed with the social-economical scale which settles the black population in the underemployed and destituded portion of the society despite the juridical equality established by the Federal Constitution. Contradictions in the Law System itself, the continuous action of the mass communication showing racial stereotypes and the prejudiced official educational system maintain the imbelievable situation the Afro-Brazians live in this country. Also, the racial prejudice in the working field is a reality. There ought to be changes in this unjust order. Discrimination must be considered a crime. A total reevaluation of the role of the negro in the History of Brazil as well as thier true political participation in our society urge to happen. Law System of 1988 . Law no $7.716 / 88$.

Unitermos: Discriminação Racial; Negros; Racismo; Discriminação Racial no Emprego.

Sob a óptica jurídica, a problemática vivida pelos afrobrasileiros, nos aponta uma questão dual, que diz respeito às importantíssimas posiçōes ocupadas pelo elemento negro na ordem jurídica brasileira: 1530 a 1888 - a) objeto de direito e ou sujeito de direito; após 1888 - b) sujeito de direito.

As contradiçōes jurídicas revelam um ordenamento composto por regras impostas por uma elite, permanecendo o povo alijado do exercício do poder político. Ditado por elites (cultural, financeiras e/ou agrária), o Direito brasileiro não promoveu como não promove o desenvolvimento sócio-econômico. Ele não revoluciona, pelo contrário, vem confirmando posiçōes de mando em de- 
trimento do exercício dos direitos humanos (individuais e sociais) propugnadas pelas Constituiçōes brasileiras.

O Brasil não possui seu "Código Negro", materialmente falando, a exemplo de outros estados americanos. As leis referentes aos escravos permaneceram esparsas em normas das Ordenaçōes Manuelinas, Filipinas e após 1822, em leis de natureza civil-comercial, e Código Criminal, Código de Processo Criminal, Codificação das Leis Civis, etc.

Mesmo após 1822 as Ordenações do Reino e inúmeras disposições do Direito Romano, permaneceram em vigor, utilizadas como subsidiária do Direito brasileiro para questões com escravos.

A Constituição Imperial outorgada por Dom Pedro I em 1824 era de cunho liberal, garantia considerável, rol de direitos humanos/individuais, herdados do ideário liberal revolucionário (1789). Vigiu até 1889, permitindo o trabalho escravo (1888), sobre o qual formalmente silenciava.

\section{O Negro Objeto de Direito}

Durante quase quatrocentos anos o negro foi objeto útil de compra e venda, sujeito à hipoteca. Conforme classificação de Teixeira de Freitas, Consolidação das Leis Civis (1858), os escravos pertenciam à classe dos bens móveis, ao lado dos semoventes ${ }^{(1)}$. Com os semoventes figuravam nos contratos de terras como bens acessórios dos imóveis.

O escravo podia pertencer a mais de um proprietário, como objeto de condomínio. Nesses casos o escravo seria alugado a um dos condôminos ou a terceiros, Ord., Ls IV, Tit. 96, § 5\%:

"Tendo os herdeiros ou companheiros, alguma coisa, que não possam entre si partir sem dano, assim como escravo... não há devem partir, mas devem-na vender a cada um delles, ou a outro algum qual mais quiserem ou por se aprazimento trocarão com outras cousas... e não poderem por esta maneira avir, arrendala-ão e partirão entre sì"(2).

Os escravos, com a morte do proprietário, entravam para o acervo hereditário e junto com os demais bens eram partilhados entre os herdeiros. Os filhos dos escravos eram legalmente denominados "fructos" ou "crias". Lei no

(1) Freitas, Augusto Teixeira - Consolidação das Leis Civis, 3a ed., Rio de Janeiro, H. Garnier, Livreiro - Editor, 1896 (P. XXXVII).

(2) Malheiro, Agostinho Perdigão - Escravidão no Brasil: ensaio histórico, jurídico, social, Rio de Janeiro, Ed. Nacional, 1866, p. 81 (nota 335). 
1.237/1864, art. 4ㅇ, item II, se refere aos nascituros escravos, como "acessões naturais" :

O escravo podia ser alforriado a título oneroso ou gratuito, por carta, testamento ou disposição de lei. Também no ato do batismo o senhor podia declarar livre seu escravo. Como ato de liberalismo a alforria era condicionada a prazos, cláusulas adjetas, condiçōes. A prestação de serviços era o modo mais utilizado, fosse ao próprio proprietário ou a terceiros por ele indicado durante lapso de tempo.

Todavia as alforrias podiam ser revogadas por ingratidāo do liberto para com seu patrono. Vigiam disposiçōes das Ordenaçōes do Reino, Livro IV, Título $63, \S 7^{\circ}$, afrontando a Constituição Imperial (art. 79 ), porque pela alforria o escravo entrava para o mundo livre. Tornava-se cidadão, brasileiro, entretanto, revogada a alforria, ocorria a reescravização, com a perda dos direitos de cidadão. Ocorre que a Constituição brasileira não previa perda de cidadania nessas condiçōes ${ }^{(3)}$.

O Código Criminal (art. 179) define como crime a redução de pessoa livre à escravidão, mesmo assim aplicava-se as disposições Filipinas; prevalecendo os interesses econômicos dos senhores.

Inclusive a interpretação dada no artigo 179 da Constituição Imperial era drástica. Este dispositivo assegurava os direitos individuais: vida, liberdade, segurança e também o direito à propriedade. Pois bem, justamente esta norma constitucional/liberal foi evocada perante o Tribunal Superior de Justiça, em defesa de proprietários, que utilizavam suas escravas no meretrício. E, aquela Suprema Corte acolheu o "rufianismo" permitindo ao proprietário o livre uso de seus bens/escravos ${ }^{(4)}$.

\section{a) Conseqüências}

- O grupo afrobrasileiro sofrerá ininterrupta agressão aos seus direitos de personalidade, direitos inerentes à pessoa. Nāo se torturou, espancou os negros inconscientemente, mas para anular a personalidade (a aptidāo para ser pessoa) e transformar um homem em escravo. Trata-se de direitos que integram o homem, são essenciais à pessoa: vida, liberdade, direito ao nome, à reputação, à honra, à imagem, à criação intelectual, o direito ao próprio corpo, etc. Sem eles a pessoa não existe como tal!

(3) Malheiro, Agostinho Perdigão, Op. Cit., p. 190 e segs. (Parte I).

(4) Morais, Evaristo de - A Campanha Abolicionista, R. de Janeiro, Livraria Editora Leite Ribeiro, 1924, p. 17 e segs. 
- As vendas e trocas separou entes queridos, impedindo a formação do núcleo social básico, a família. Esta situação ficará mais clara quando estudiosos (sociólogos, historiadores) pesquisam a política imigratória ${ }^{(5)}$. O sucesso do imigrante europeu e asiático dependeu, como se comprovou, da proteção às familias imigrantes. Das providências legais com vista à integração da família imigrante ao povo brasileiro.

\section{O Negro Sujeito de Direito}

Apenas o ser humano é sujeito de direitos e obrigaçōes. Mas para o Direito Penal brasileiro, o negro era uma pessoa especial. Não para ter sua vida, seu patrimônio protegido, mas para ser mais severamente punido que as pessoas livres.

E, desde a chegada dos primeiros escravos africanos ao Brasil (1530) até 1888 , negro era sinônimo de escravo e branco era sinônimo de livre/cidadão.

Nossa Constituição de 1824 de caráter liberal estabelecia no citado art. 179: "no 18 - Organizar-se-á quanto antes um Código Civil e Criminal fundado nas sólidas bases da Justiça e da eqüidade"; " $n$ - 19 - Desde já ficam abolidos os açoites, a tortura, a marca de ferro quente, e todas as mais penas cruéis".

Entretanto, o Código Criminal que veio à luz em 1830 impunha as tais penas cruéis ao escravo, já proibidas pela Carta Magna, justamente quando este resistisse à escravizaçāo. Isso em pleno florescimento da doutrina liberal.

O art. 60 do Código Criminal do Império é grotesco em sua severidade: "Se o Réu for escravo, e incorrer em pena que não seja capital ou de galés será condenado na de açoites e, depois de os sofrer, será entregue a seu senhor, que se obrigará a trazê-lo com um ferro, pelo tempo e maneira que o juiz designar"'(6).

O princípio do contraditório e demais garantias processuais eram obrigados pela Constituição Imperial. O Código de Processo Criminal promulgado em 1832, art. 332 exigia votação unânime sobre fato criminoso para a imposição da pena capital ${ }^{(7)}$. E mais uma vez, venceu o racionarismo escravista, com o ad-

(5) Amado, Janaína - Constituição ao Estudo de Imigração Alemão no Rio Grande do Sul (São Leopoldo - 1824-1874) in Rev. Ciência e Cultura SBPC, vol. 29 no 7/1977, p. 748 e Nota no 23 .

(6) Brasil, Leis, decreto, etc. - Código Criminal de Império do Brasil, 2a Ed: Rio de Janeiro, Ed. Eduardo de Henrique Lemmert, 1876.

(7) Azevedo, Noé - As Garantias da Liberdade Individual em Face das Novas Tendências Penais, São Paulo, Rev. Tribs., 1 936, p. 37. 
vento da Lei no 4 , de 10 de junho de 1835 . Submetia a rigoroso processo o réuescravo acusado, pois simplesmente alterou a exigência para $2 / 3$ do número de votos para condenação do réu/escravo à pena de morte. Sem cogitar do grau de culpabilidade. $\mathrm{O}$ escravo acusado era julgado pelo Juiz do termo mais próximo e da sentença condenatória não cabia recurso.

A existência de leis cruéis, como a de no 4/1835 deixa clara a tenaz resistência do negro à escravidão, e a utilização do Direito como instrumento de opressão.

\section{A Liberdade Formal}

Somente um conflito internacional de grandes proporçōes, envolvendo interesses capitalistas da Inglaterra, - Guerra contra o Paraguai -, seguida de revoltas intestinas promovidas pelos negros ex-combatentes, vitoriosos; conseguiram desarticular o sistema escravista no Brasil. São as mesmas armas utilizadas na Guerra do Paraguai que promovem fugas maciças de escravos e a formação de novos quilombos.

Segue-se a libertação gradual dos escravos:

a) Lei dos Sexagenários, Lei no 3.270, de 28 de setembro de 1885, libertava os proprietários dos velhinos improdutivos; b) Lei do Ventre Livre, Lei no 2.040, de 28 de setembro de 1871, cujo primeiro artigo dizia: "Art. 19- Os filhos da mulher escrava, que nascerem no império desde a data desta lei, serão considerados de condição livre". "§ 10- Os ditos fillhos menores ficarão em poder e sob autoridade dos senhores de suas mães, os quais terão obrigação de criá-los até a idade de oito anos completos". Chegando o filho da escrava a esta idade o senhor da mãe terá a opção ou de receber do estado a indenização de $600 \$ 000$ ou de utilizar-se dos serviços do menor até 21 anos completos".

Na realidade, o proprietário recebia a indenização e os menores eram entregues pelo Estado às associaçōes e terminavam abandonados pelas ruas das cidades, da mesma forma que os velhinhos sexagenários.

\section{O Negro e a Política Imigratória}

D. João VI (1808) ficou estarrecido com o Brasil que conheceu. A populaçāo negra era mais numerosa que a branca, e em Decreto de 25 de novembro de 1808 inicia a política imigratória para o Brasil, "de gentes brancas livres".

(8) Morais, Evaristo, Op. Cit., p. 3. 
As primeiras leis referentes à imigração são manifestamente racistas e os povos recebidos provinham do Norte da Europa ${ }^{(9)}$ : Pedro (RS);

- Carta Régia de 23 de setembro de 1811, colonos irlandeses para São (RJ);

- Decreto de 6 de maio de 1828, colonos suíços para Nova Friburgo

- Decisão no 80 , de 31 de março de 1824, colonos alemães para São Leopoldo (RS); etc.

A primeira disposição legal que admite imigrantes europeus, sem exigir origem, data de 1874, Decreto n- 5.524, de 7 de janeiro de 1874. E realmente desta data até 1900 o Brasil recebeu 803.000 imigrantes, sendo 577.000 provenientes da Itália ${ }^{(10)}$.

No Brasil a pirâmide sócio-econômica é racial, o contingente afrobrasileiro engrossa a base desta pirâmide entre os assalariados e subempregados. Os imigrantes europeus, asiáticos e seus descendentes permeiam todas as classes sociais brasileiras.

O Direito brasileiro exerceu funçōes distintas com referência aos dois grupos:

Leis Imigratórias $=$ Direito com vistas à Promoção Humana: caráter benéfico: 1. salário; 2. proteção à família; 3. educação às crianças; 4. reconhecimento do casamento protestante; 5 . respeita lideranças oficiais: diplomatas, padres, pastores. Objetivo = integrar a familia imigrante ao Brasil.

Leis Escravistas = Direito mantenedor do "status quo": caráter punitivo: 1. destruição do ego; 2. descaracterização da cultura; 3. sujeição à prisão e às penas domésticas; 4 . impedimentos à formação de núcleo familiar; 5. proibição à qualquer ação conjunta; 6 . disseminação do medo/desconfiança; 7. morte às lideranças. Objetivo $=$ dividir para submeter.

\section{Negro Cidadão}

A Lei no 3.353, de 13 de maio de 1888, aboliu a escravidāo; a partir da Lei Áurea o negro brasileiro é cidadão, titular de direitos e obrigaçōes.

(9) Demoro, Luis - Coordenação de Leis de Imigração e Colonização do Brasil, Rio de Janeiro, Departamento de Estudos e Planejamento, Instituto Nacional de Imigração e Colonização, 1960, p. 32.

(10) Dallari, Dalmo de Abreu - O Pequeno Exército Paulista, São Paulo, Perspectiva, 1977 , p. 5. 
Tal titularidade constitui mera formalidade, uma vez que, não será recebido como trabalhador livre no mercado de trabalho. Prefere-se o imigrante.

Não se nota qualquer providência legal, com vistas à integração dos novos cidadãos, pelo contrário, o jurista Rui Barbosa, Ministro da Fazenda do Governo provisório republicano, promoveu a incineração de documentos referentes à escravidão africana no Brasil. Seu objetivo imediato era impossibilitar cobrança de indenizações prometidas pelos republicanos aos senhores de escravo, mas acabou por causar irreparável prejuízo à recuperação da memória nacional $^{(11)}$.

O menosprezo para com o negro, por parte daqueles que até 1888 (o advento da República foi em 1889) eram abolicionistas, fica claro quando se pesquisa as leis imigratórias. Decreto no 528, de 28 de junho de 1890 em seu artigo 1ํ, é taxativo: '‘́́ inteiramente livre a entrada, por portōes da República, dos indivíduos válidos e aptos para o trabalho... excetuados os indígenas da Ásia e da África...".(12).

Ora, o direito ao trabalho também é fundamental para aqueles que possuem somente sua força de trabalho para oferecer à sociedade. $O$ trabalho é o instrumento para se atingir os demais direitos sociais fundamentais (saúde, educação, etc.). Se não fosse a mulher negra garantir a sobrevivência de sua família, trabalhando como empregada doméstica, a raça negra não teria sobrevivido à miserabilidade das primeiras décadas de cidadania!

A primeira Constituição brasileira de cunho social foi promulgada em 1934 e ao lado dos direitos individuais-tradicionais, garante os direitos sociais (reconhecimento dos sindicatos, melhores condições de trabalho, salário mínimo, descanso semanal remunerado, férias anuais, assistência médica e sanitária ao trabalhador, proteção ao menor e a mulher trabalhadora).

O incremento da industrialização nas cidades do Sudoeste brasileiro, a exigência de concurso para ocupar cargos públicos; a implantação de escolas públicas gratuitas, cursos notumos e profissionalizantes; bem como a ação contestatória ininterrupta de Associaçōes Negras, destaque-se a Frente Negra Brasileira (extinta pela ditadura Vargas em 1937), possibilitaram ao negro iniciar com décadas de atraso a concorrência com os imigrantes e seus descen-

(11) Simonsen, Roberto C. - As Conseqüências Econômicas da Abolição - (Conferência Comemorativa do 1\% Cinqüentenário da Abolição - I de Maio de 1938) in Ensaios Políticos e Econômicos, São Paulo, Federação das Indústrias do Estado de S. Paulo, janeiro, 1943, p. 23.

(12) Rodrigues, José Honório - África e Brasil, Outro Horizonte, 2ª ed., R. de Janeiro, Civilização Brasileira, 1964, p. 86. 
dentes. A despeito de o Decreto-Lei no 7.967, de 18 de setembro de 1945 (Getúlio Vargas), declarar em seu artigo 20. "Atender-se-á na admissão dos imigrantes, à necessidade de preservar e de desenvolver, na composição étnica da população, as características mais convenientes de sua ascendência européia, assim como a defesa do trabalhador nacional", (13) grifo nosso.

\section{Discriminação Racial: Crime Contra a Pessoa}

A primeira lei brasileira contra a discriminação racial é a Lei no 1.390 , de 3 de julho de 1951 de autoria do então deputado federal por Minas Gerais, Dr. Afonso Arinos de Melo Franco.

Tipifica a prática de raciscmo como mera contravenção penal, ora é visível a todos que a discriminação racial fere a integridade física e psíquica. É portanto crime e dos mais graves. $\mathrm{O}$ autor em suas memórias afirma: " $O$ texto não sofreu nenhuma modificação, nem na Câmara nem no Senado, a não ser uma emenda que eu mesmo apresentei, quando do trânsito do projeto pela Comissão de Justiça, incluindo a figura de contravenção por negativa de trabalho em empresa pública ou privada, por preconceito de cor"(14).

Imagine-se, além de definir prática criminosa como infraçāo leve, justamente o racismo no mercado de trabalho sequer constava do projeto de lei. Mesmo com esta correção, a Lei Afonso Arinos apresentava-se casuística e desatualizada.

Observe-se fato recente, ocorrido em São Paulo, quando os proprietários de casa noturna são acusados de impedir a entrada de jovem negra em seu estabelecimento, por motivo de raça.

Trata-se do Processo no 134/85, 8 a Vara Criminal da Comarca de São Paulo. Os acusados alegaram inocência e que a recusa seria motivada pelo fato de a festa ter caráter "privê". Realmente, tal modalidade de festividade não era contemplada pela casuística Lei $n^{\circ} 1.390$. E ao juízo penal não se permite o uso de analogia.

A sentença absolutória, proferida pelo MM. Juiz, Dr. R. Paulo Miguel de Campos Petroni, merece protesto e sobretudo reflexão, tão pasmados permanecem com os conceitos, ali emitidos, sobre a mulher negra:

'J.S.S.; A.T.N.; R.J.O.F.; A.C.S., foram acusados com base no art. 4 da Lei 1.390/51, constando terem em 26.6 e 4.2.85, em estabelecimento

(13) Rodrigues, José Honório, Op. Cit., p. 93.

(14) Franco, Afonso Arinos de Melo - A Escalada: Memórias. Rio de Janeiro, José Olympio, 1965, p. 177. 
noturno, impedido a entrada das vítimas H.O.M.O. e D.O., por serem de cor preta. Consta que alegaram tratar-se de festa privativa e o último confirmou o preconceito racial.

Proc. policial judicialmente do 4 Dist., e em Juízo, interrogados, negaram a imputação, vindo prévias com testemunhas, ouvidas.

O Dr. Promotor manifestou-se pela absolvição, entendendo nāo provada a acusação, tendo sido seguido pela defesa.

Relatado, decido.

Depois de minucioso parecer ministerial de páginas 153-157, que endosso, nada mais resta, a não ser absolver os quatro acionados.

Realmente, a ofendida não foi barrada por questão racial, e nem ela é propriamente negra. Parece mais para branca que para mulata, pelas duas fotos juntadas.

Tratava-se de festa "privê", estando o "club" alugado, como é comum, mas mesmo assim, foi ela atendida, recebendo explicações.

Os réus nunca admitiram a acusação, e um deles apenas falou que a "burguesia paulistana" (?!) acha que se pretos freqüentarem o local, o nível cairá. Mas essa absurda opinião não foi do acionado, que expressamente declarou nada ter contra os negros.

Não houve segregação racial.

No Brasil, esta praticamente não existe. Os negros são queridos, ídolos não só nos esportes, músicas, cinema, etc., e as mulatas, sem qualquer dúvida, são cobiçadas pela grande maioria dos homens, sejam brancos ou pretos. Aliás, as "amarelas" também.

Infelizmente, há muito mais segregação social e econômica, que racial, mas isso, data maxima venia, não configura o delito da inicial.

Tanto é, que processos, com base na antiga "Lei Afonso Arinos" são raríssimos, mesmo havendo juristas da tez escura.

Ficam os quatro absolvidos, conforme art. 386 IV do CPP. Acolho também os argumentos da defesa, lembrando que são os réus primários". 


\section{Sistema Constitucional Vigente}

O direito tão cioso no passado, em defesa dos direitos da sociedade escravista, hoje, pune brandamente a discriminação, além da má redação que a Lei no 1.390/51 apresentava.

Afinal, quando o legislador pretendeu (realmente!) proteger o principal bem da humanidade - a vida, foi simples e objetivo, Código Penal:

“Art. 121 - Matar alguém: Pena - reclusão de 6 a 20 anos".

Tal situação foi revista pela Assembléia Nacional Constituinte e conforme artigo 5 da Constituição Federal de 1988; temos:

"XLIII - A prática do racismo constitui crime inafiançável e imprescritível, sujeito a pena de reclusão, nos termos da lei”.

Ainda em 1988 foi apresentado o Projeto de Lei no 668/88 (Câmara dos Deputados) de autoria do ilustre deputado Carlos Alberto Caó (PDT), antigo presidente da Associação Brasileira de Imprensa, tipificando como crime atos resultantes de preconceito de raça ou de cor. Após aprovação pela Câmara tomou o no PLC no 52/88, no Senado Federal, enviado para sanção, teve vetados os artigos $2^{\circ}, 15,17$ e 18 pelo Presidente Sarney.

Afinal em 5 de janeiro de 1989 veio à luz a Lei no 7.716, Lei Caó, marco histórico na legislação brasileira, reivindicação antiga das lideranças afrobrasileira e de toda a sociedade civil, voltada para a proteção dos direitos humanos:

\section{“LEI № 7.716 - DE 5 DE JANEIRO DE 1989}

Define os crimes resultantes de preconceitos de raça ou de cor

Art. 1\%. Serão punidos, na forma desta Lei, os crimes resultantes de preconceitos de raça ou de cor.

Art. 2\%. (Vetado).

Art. 3\%. Impedir ou obstar o acesso de alguém, devidamente habilitado, a qualquer cargo da Administração Direta ou Indireta, bem como das concessionárias de serviços públicos:

Pena: reclusão de 2 (dois) a 5 (cinco) anos.

Art. 4-. Negar ou obstar emprego em empresa privada:

Pena: reclusão de 2 (dois) a 5 (cinco) anos. 
Art. 5\%. Recusar ou impedir acesso a estabelecimento comercial, negando-se a servir, atender ou receber cliente ou comprador:

Pena: reclusão de 1 (um) a 3 (três) anos.

Art. 6-. Recusar, negar ou impedir a inscrição ou ingresso de aluno em estabelecimento de ensino público ou privado de qualquer grau:

Pena: reclusão de 3 (três) a 5 (cinco) anos.

Art. 7․ Impedir o acesso ou recusar hospedagem em hotel, pensão, estalagem, ou qualquer estabelecimento similar:

Pena: reclusão de 3 ( três) a 5 (cinco) anos.

Art. 8․ Impedir o acesso ou recusar atendimento em restaurantes, bares, confeitarias, ou locais semelhantes abertos ao público:

Pena: reclusão de 1 (um) a 3 (três) anos.

Art. 99. Impedir o acesso ou recusar atendime nto em estabelecimentos esportivos, casas de diversōes, ou clubes sociais abertos ao público:

Pena: reclusão de 1 (um) a 3 (três) anos.

Art. 10. Impedir o acesso ou recusar atendimento em salōes de cabeleireiros, barbearias, termas ou casas de massagem ou estabelecimentos com as mesmas finalidades:

Pena: reclusão de 1 (um) a 3 (três) anos.

Art. 11. Impedir o acesso às entradas sociais em edifícios públicos ou residenciais e elevadores ou escada de acesso aos mesmos:

Pena: reclusão de 1 (um) a 3 (três) anos.

Art. 12. Impedir o acesso ou uso de transportes públicos, como aviōes, navios, barcas, barcos, ônibus, trens, metrô ou qualquer outro meio de transporte concedido:

Pena: reclusão de 1 (um) a 3 (três) anos.

Art. 13. Impedir ou obstar o acesso de alguém ao serviço em qualquer ramo das Forças Armadas:

Pena: reclusão de 2 (dois) a 4 (quatro) anos.

Art. 14. Impedir ou obstar, por qualquer meio ou forma, o casamento ou convivência familiar e social:

Pena: reclusão de 2 (dois) a 4 (quatro) anos.

Art. 15. (Vetado).

Art. 16. Constitui efeito da condenação a perda do cargo ou função 
pública, para o servidor público, e a suspensão do funcionamento do estabelecimento particular por prazo não superior a 3 (três) meses.

Art. 17. (Vetado).

Art. 18. Os efeitos de que tratam os artigos 16 e 17 desta Lei não são automáticos, devendo ser motivadamente declarados na sentença.

Art. 19. (Vetado).

Art. 20. Esta Lei entra em vigor na data de sua publicação.

Art. 21. Revogam-se as disposições em contrário".

Todavia às providências de ordem legal deverão juntar-se alterações profundas na educaçāo oficial, pois há muito pesquisadores de áreas diversas vêm demonstrando que o elemento negro foi um agente civilizador, ao lado de outros povos formadores das nações americanas. Urge ampla revisão na História do Brasil.

Quanto à educação informal aguarda-se, sobretudo dos meios de comunicação de massas, atuação decente com referência à imagem dos afrobrasileiros, diurturnamente deturpada; incentivando práticas racistas.

Note-se que o artigo 15 do citado Projeto de Lei no 668/88, que agravava as penalidades quando a discriminação racial fosse praticada por órgãos da imprensa, foi vetado pelo Executivo. Porém, os representantes do povo opinarão quando da elaboração de contratos de concessão para particulares explorarem os serviços de radiodifusão sonora, de som e imagens e demais serviços de telecomunicações.

A Constituição Federal de 1988 é inovadora:

“Art. 49 - É da competência exclusiva do Congresso Nacional:

XII - apreciar os atos de concessão e renovação de concessão de emissoras de rádio e televisão".

Os efeitos da Lei no 7.716 no meio social dependem agora dessas providências somadas à ação ininterrupta da sociedade civil, da qual o "movimento negro" (associaçōes afrobrasileiras) constitui parte integrante.

\section{REFERÊNCIAS BIBLIOGRÁFICAS}

AMADO, Janaina - Contribuição ao estudo da imigração alemã no Rio Grande do Sul; São Leopoldo, 1824-1874. Revista Ciência e Cultura, São Paulo, 29(7): 735-7, jul. 1977. 
ARARIPE, Tristão de Alencar - Código Civil Brasileiro, ou Leis Civis do Brasil, Rio de Janeiro, Laemmert, 1885

ARARIPE, Tristão de Alencar - Consolidação do processo criminal do Brasil. Rio de Janeiro, Cruz Coutinho, 1876.

AZEVEDO, Noé - As garantias da liberdade individual em face das novas tendências penais. São Paulo, Ed. Revista dos Tribunais, 1936. Tese (livre-doc.). Fac. Dir. USP.

BANDECCHI, Brasil - Conceituação do escravo face às escrituras de compra e venda. Separata da Revista do Instituto de Estudos Brasileiros, São Paulo, Inst. Est. Bras. USP, 8, 1970.

BASAVE, Agustim - La dimension jurídica del hombre; fundamentos antropológicos de la filosofia del derecho. Revista de Informação Legislativa, Brasilia, Senado Federal, 9(36): 31-6, out./dez. 1972.

BRASIL, Leis, decretos, etc. - Código Penal; decreto-lei no 2.848 , de 7 de dezembæo de 1940, atualizado pela legislação posterior, inclusive pela Lei no 6.416/77, São Paulo, Saraiva, 1980.

BRASIL, Leis, decretos, etc. - Colleção das leis do Império do Brasil, 2ª ed. Ouro Preto, Tip. Silva, 1835, v. 3.

BRASIL, Leis, decretos, etc. - Constituição da República Federativa do Brasil, 1967; emenda constitucional $n^{\circ}=1$, de 17 de outubro de 1969, 17ª ed. Sāo Paulo, Saraiva, 1979.

BRASIL, Leis, decretos, etc. - Constituiçāo do Brasil. Org. Car. os Eduardo Barreto, 6ª ed. rev. e atual. São Paulo, Saraiva, 1971, 2 v.

BUENO, Jose Antônio Pimenta - Direito público brasileiro e analyse da Constituição do Império. Rio de Janeiro, Villeneeueu, 1857.

CHIAVENATO, Júlio José - O Negro no Brasil: da senzala à guerra do Paraguai, São Paulo, Brasiliense, 1980, $259 \mathrm{p}$.

CRETELla JÚNIOR, José - Dicionário de Direito Administrativo, 3a ed., Rio de Janeiro, Forense, 1976.

DALLARI, Dalmo de Abreu - Consciência negra. Folha deS Paulo, São Paulo, 25 nov. 1979. Tendências/Debates.

DALLARI, Dalmo de Abreu - Constituição e revolução do estado brasileiro, Revista da Faculdade de Direito, São Paulo, 72(1): 325 -34, 1977. Número especial em comemoração ao Sesquicentenário da Fundação dos Cursos Jurídicos no Brasil.

DALLARI, Dalmo de Abreu - O futuro do estado. São Paulo, Saraiva, 1972.

DALlARI, Dalmo de Abreu - O pequeno exército paulista. São Paulo, Perspectiva 1977.

DALlARI, Dalmo de Abreu - Vivem em Sociedade, São Paulo, Ed. Moderna, 1985. 
DEMORO, Luis - Coordenação de leis de imigração e colonização do Brasil, Rio de Janeiro, Dep. Est. Plan. Inst. Nac. de Imigração e Colonização, 1960.

FER ANDES, Forestan; NOGUEIRA, Oracy; PEREIRA, João Batista Borges - A questão racial brasileira vista por três professores. A Gazeta, São Paulo, 27 ago. 1966. Entrevista.

FERREIRA FILHO, Manoel Gonçalves - Comentários à Constituição Brasileira; emenda constitucional no $=1$, de 17 de outubro de 1969, 2ª ed. São Paulo, Saraiva, 1977, 3 v.

FERREIRA FILHO, Manoel Gonçalves - Curso de Direito Constitucional - 17ª ed., rev. e atual. São Paulo, Saraiva, 1989.

FIGUEIRAS JÚNIOR, Araújo - Código Criminal do Império do Brasil, 2ª ed., Rio de Janeiro, Laemmert, 1876.

FRANCO, Afonso Arinos de Melo - A escalada; memórias. Rio de Janeiro, José Olympio, 1965.

FREITAS, Augusto Teixeira - Consolidação das Leis Civis, 3ª ed., Rio de Janeiro, Garnier, 1896.

GALLO, Jorge Ivan Hubner - La igualdad desde el punto de vista filosófico, social y juridico. Revista de Informação Legislativa, Brasília, Senado Federal, 9(36): 113-20, out./dez. 1972.

GARCIA, Basileu - Instituições de Direito Penal, 4ª ed., São Paulo, Max Limonad, 1976, v. $1 . t .1$, t. 2.

IBGE (OLIVEIRA, Lúcia Elena Garcia - PORCARO, Rosa Maria; e ARAÚJO, Tereza Cristina N.) - O Lugar do Negro na Força de Trabalho/Fundação Instituto Brasileiro de Geografia e Estatística, Rio de Janeiro, IBGE, 1981.

MALHEIRO, Agostinho Marques Perdigão - Escravidão no Brasil; ensaio histórico, jurídico, social. Rio de Janeiro, Ed.N acional, 1866.

MORAIS, Evaristo de - A campanha abolicionista. Rio de Janeiro, Ed. Leite Ribeiro, 1924.

MOURA, Clóvis Steiger de Assis - Os Quilombos e a Rebelião Negra, São Paulo, Brasiliense, 1988.

MOURA, Clóvis Steiger de Assis - Brasil: Raízes do Protesto Negro, São Paulo, Global, 1983.

NASCIMENTO, Abdias do - O Negro Revoltado, Rio de Janeiro, Nova Fronteira, 1982.

PRUDENTE, Celso - Pedagogia da Violência Racial, Folha de S. Paulo, São Paulo, 19 de fevereiro de 1988, p. 10.

PRUDENTE, Eunice Aparecida de Jesus - Preconceitos Racial e Igualdade Jurídica no Brasil - A Cidadania Negra em Questão. Campinas (SP), Ed. Julex,1 988. 
RODRIGUES, José Honório - Independência, revoluçāo e contra revolução; a liderança nacional. São Paulo, Francisco Alves \& EDUSP, 1975.

RODRIGUES, José Honório - África e Brasil - Outro Horizonte, 2ª ed., Rio de Janeiro, Civilização Brasileira, 1964.

SANTOS, Hélio - Chegou a Hora de Refletir, Revista Veja, São Paulo, 16 de junho de 1982, p. 162.

SILVEIRA, Alípio - Prevenção da criminalidade a partir das suas raízes, $2^{a}$ ed., São Paulo, Ed. Universitária de Direito, 1979.

SIMONSEN, Roberto C. - As conseqüências econômicas da abolição. In ENSAIOS sociais, políticos e econômicos. São Paulo, Fiesp, 1943, p. 20-39.

São Paulo, novembro de 1989. 